\title{
Gastric GIST: When Can We Think About It?
}

\author{
George Mantese ${ }^{*}$ \\ ${ }^{1}$ Secretaria Municipal de Saúde de Porto Alegre, Porto Alegre, Brazil
}

Corresponding Author: George Mantese, MD, Secretaria Municipal de Saúde de Porto Alegre, Porto Alegre, Brazil. Tel: +5551997511290, Email: georgemantese@hotmail.com

Received February 22, 2019; Accepted April 22, 2019; Online Published June 15, 2019

\begin{abstract}
This study analyzes the symptoms of gastrointestinal stromal tumor (GIST) and its causes from a clinical view to determine when people can say that they suspect a tumor. GIST is a sarcoma that is not common in people; however, even those who have it find it hard to notice, because it does not have symptoms. Furthermore, it does not affect a person in the early stages. The challenge extends to medics who can easily confuse the tumor with another gastric sarcoma. The tumor affects the stomach more, followed by the small intestines, and then the rectum. The cause of the disease is still unknown, although doctors associate it with several inherited syndromes. Syndromes, such as primary familial syndrome, result in a tumor by affecting the gastric tract muscle cells. Some of the symptoms that are likely to show that a person has a sarcoma include abdominal pain and a feeling of fullness earlier than one expects. Doctors can compare these symptoms with the cause of GIST and emphasize the possibility of the presence of a tumor.

Keywords: Gastrointestinal Stromal Tumor (GIST), Interstitial Cells of Cajal (ICC), Syndrome, Symptoms, Abdomen

Citation: Mantese G. Gastric GIST: when can we think about it? Int J Med Rev. 2019;6(2):37-39. doi:10.29252/IJMR-060202.
\end{abstract}

\section{Introduction About GIST in Special Gastric GIST}

A gastrointestinal stromal tumor (GIST) is a soft tissue sarcoma which grows as loose tissue and spreads across the gastrointestinal (GI) track. The tumor is not common, occuring in less than $1 \%$ of GI tumors, although it is the most common mesenchymal neoplasm to affect the GI tract. ${ }^{1,2}$ Sarcoma can occur anywhere along the GI, but it is common in the stomach and small intestine. The tumor varies in characteristics depending on the location, size, and cell division. Tumor size can vary between $4 \mathrm{~mm}$ and $35 \mathrm{~cm} .{ }^{1}$ The characteristics determine whether the GIST expands to other areas of the body. GISTs occur in the interstitial cells of Cajal (ICC), also called the "pacemakers".,4 The cells belong to the autonomic nervous system, which is responsible for regulating processes of the body like food digestion. ICCs signal the GI to contract and relax the muscles to allow food and other liquids to flow. ${ }^{5}$

Although there is not much information about the risk factors of GIST, it is known to affect people between the ages of 40 and 80 years. ${ }^{6}$ Also, there is a rare uninherited risk factor, a gene mutation, which increases the chance of a person developing GIST. Another risk factor is the primary familial GIST syndrome, an inherited condition. ${ }^{1}$ The syndrome can lead to the development of GIST at an earlier age than the expected 40 years and in more than one form. Primary familial GIST syndrome originates from KIT, an abnormal gene that a child inherits from parents. ${ }^{7}$ The abnormal gene is found in all cells of those people who inherit it and in cancer cells for those with sporadic GIST. The syndrome can also result from a change in the PDGFRA gene. ${ }^{8,9}$ Another risk factor of GIST is the neurofibromatosis type 1 disease which results from the defected NF1 gene, and it can be inherited. ${ }^{1,4}$ Moreover, Carney-Stratakis syndrome, also an inherited condition, creates the risk for developing GIST at early ages.

\section{Symptoms of Special Gastric GIST}

Some symptoms which may suggest that a person has GIST include upper abdominal pain, abdominal fullness, nausea, heartburn, or a feeling of being full earlier than expected. ${ }^{1,10} \mathrm{~A}$ patient may also have blood in the stool or experience acute hematemesis.

\section{Doctors' Exclusion of More Common Causes}

Abdominal pain, a feeling of early fullness, and abdominal fullness may result from the insensitivity of the ICCs. The cells may become unable to regulate gastric activities, leading to a hardening of the walls, which makes one feel full or even pain. Moreover, one may feel full earlier than usual, because the GI is not allowing food to flow in the stomach due to the failure of muscle contraction. ${ }^{11-13}$ GIST is one cause of inactiveness in ICCs, which may make the IG muscle cells unable to respond. It also prevents mutation in KIT genes, ${ }^{1}$ and the inhibition increases the symptoms of dyspepsia. ${ }^{14}$ Because of these facts, doctors may think of GIST on seeing the amplified symptoms of dyspepsia. The function of the KIT gene is to help in the development and role of some cells once it receives signals. ${ }^{7,15-17}$ The KIT gene helps those ICCs found in the GI to function and develop. When tumors inhibit KIT proteins, they do not

Copyright $\odot 2019$ The Author(s). This is an open-access article distributed under the terms of the Creative Commons Attribution License (http:// creativecommons.org/licenses/by/4.0), which permits unrestricted use, distribution, and reproduction in any medium, provided the original work is properly cited. 
develop or coordinate the function of the ICC, and therefore, abdominal activities are halted, which provokes the symptoms described above. Because GIST inhibits the KIT gene, doctors may think of such a tumor when they see such signs.?

Nausea, heartburn, or abdominal pain may occur because of the inhibition of the peritoneum structure, which produces fluid in the abdomen to allow food to move smoothly.1,18,19 The inhibition occurs when another layer forms on top of the peritoneum, blocking the fluid from reaching the stomach. When the layer cannot produce the fluid or the fluid does not reach the abdomen, a person feels pain because of the increased friction in the stomach, heartburn, and nausea. GIST inhibits the production of gastric fluid in the peritoneum by forming a layer on top. ${ }^{20,21}$ This condition occurs when GIST from the GI metastasizes in an abnormal way to the abdominal wall. ${ }^{17,22} \mathrm{~A}$ doctor, therefore, may think of GIST when there is a combination of symptoms including abdominal pain, nausea, and heartburn.

Blood in the stool and hematemesis are indications of a bleeding abdominal wall or intestines. Because of transmural growth, GISTs may grow to enormous sizes, ${ }^{1}$ and they have many blood vessels around them. ${ }^{1,20}$ The size may cause the blood vessels to stretch to such an extent that they leak blood. Furthermore, as a person takes in food, the tumor is scratched and begins to bleed. The blood exits through the mouth when it is too much or goes through the intestines and is released through the stool. Symptoms of blood in the stool and hematemesis, therefore, may lead a doctor to think of GIST.

\section{Conclusions}

This study aimed to determine when patients can gain insight into GIST from some symptoms. Primary sources including peer-reviewed journals were employed to understand what GIST is, its causes, and its symptoms. It was found that GIST is a tumor which attacks the soft tissue and grows across the GI tract. A person can have an uninherited risk factor in the form of a gene mutation or an inherited risk factor leading to sarcoma. Although GIST can occur anywhere along the GI, it more commonly affects the small intestines and the stomach. Symptoms include an early feeling of fullness, abdominal fullness, abdominal pain, blood in the stool, and hematemesis. With such symptoms, patients may think of gastric issues, but further analysis from a clinician is required to strengthen the insights.

Abdominal pain, a feeling of early fullness, and abdominal fullness may result from the insensitivity of ICCs. The cells may become unable to regulate gastric activities, leading to hardening of the walls which makes one feel full or even pain. GIST is one of the conditions which can inhibit the functioning of ICCs, and therefore, a gastroenterologist can conclude there is a tumor upon seeing such symptoms. Clinicians should apply the knowledge from this study to help more patients who may not be aware that they have cancer. GIST is not common, and its symptoms are common to other stomach problems. Consequently, one might find it difficult to think of GIST. A gastroenterologist should seek more information from patients with stomach problems to help deermine whether they have GIST.

\section{Conflict of Interest Disclosures}

All authors declare that they have no conflicts of interest.

\section{References}

1. Menge F, Jakob J, Kasper B, Smakic A, Gaiser T, Hohenberger P. Clinical presentation of gastrointestinal stromal tumors. Visc Med. 2018;34(5):335-340. doi:10.1159/000494303.

2. Corless CL. Gastrointestinal stromal tumors: what do we know now? Mod Pathol. 2014;27 Suppl 1:S1-16. doi:10.1038/ modpathol.2013.173.

3. Ma GL, Murphy JD, Martinez ME, Sicklick JK. Epidemiology of gastrointestinal stromal tumors in the era of histology codes: results of a population-based study. Cancer Epidemiol Biomarkers Prev. 2015;24(1):298-302. doi:10.1158/1055-9965.epi-14-1002.

4. Al-Shboul OA. The importance of interstitial cells of cajal in the gastrointestinal tract. Saudi J Gastroenterol. 2013;19(1):3-15. doi:10.4103/1319-3767.105909.

5. Klein S, Seidler B, Kettenberger A, et al. Interstitial cells of Cajal integrate excitatory and inhibitory neurotransmission with intestinal slow-wave activity. Nat Commun. 2013;4:1630. doi:10.1038/ncomms2626.

6. Kramer K, Knippschild U, Mayer B, et al. Impact of age and gender on tumor related prognosis in gastrointestinal stromal tumors (GIST). BMC Cancer. 2015;15:57. doi:10.1186/s12885-0151054-y.

7. Zhu Y, Wang Y, Guan B, et al. C-kit and PDGFRA gene mutations in triple negative breast cancer. Int J Clin Exp Pathol. 2014;7(7):42804285.

8. Boikos SA, Pappo AS, Killian JK, et al. Molecular subtypes of KIT/PDGFRA wild-type gastrointestinal stromal tumors: a report from the National Institutes of Health Gastrointestinal Stromal Tumor Clinic. JAMA Oncol. 2016;2(7):922-928. doi:10.1001/ jamaoncol.2016.0256.

9. Astolfi A, Urbini $M$, Indio $V$, et al. Whole exome sequencing (WES) on formalin-fixed, paraffin-embedded (FFPE) tumor tissue in gastrointestinal stromal tumors (GIST). BMC Genomics. 2015;16:892. doi:10.1186/s12864-015-1982-6.

10. Zebary A, Jangard M, Omholt K, Ragnarsson-Olding B, Hansson J. KIT, NRAS and BRAF mutations in sinonasal mucosal melanoma: a study of 56 cases. Br J Cancer. 2013;109(3):559-564. doi:10.1038/ bjc.2013.373.

11. Iorio N, Sawaya RA, Friedenberg FK. Review article: the biology, diagnosis and management of gastrointestinal stromal tumours. Aliment Pharmacol Ther. 2014;39(12):1376-1386. doi:10.1111/ apt. 12761.

12. Hirahara N, Matsubara T, Kidani A, Hyakudomi R, Fujii Y, Tajima Y. A novel technique to minimize deformation of the stomach in laparoscopic partial gastrectomy for intraluminal gastric GISTs. J Laparoendosc Adv Surg Tech A. 2014;24(10):707-711. doi:10.1089/lap.2014.0184.

13. Huynh TK, Meeus P, Cassier P, et al. Primary localized rectal/ pararectal gastrointestinal stromal tumors: results of surgical and multimodal therapy from the French Sarcoma group. BMC Cancer. 2014;14:156. doi:10.1186/1471-2407-14-156.

14. Yu QX, He ZK, Wang J, Sun C, Zhao W, Wang BM. Clinical presentations of gastric small gastrointestinal stromal tumors mimics functional dyspepsia symptoms. World J Gastroenterol. 2014;20(33):11800-11807. doi:10.3748/wjg.v20.i33.11800.

15. Lian X, Feng F, Guo M, et al. Meta-analysis comparing laparoscopic versus open resection for gastric gastrointestinal stromal tumors larger than $5 \mathrm{~cm}$. BMC Cancer. 2017;17(1):760. doi:10.1186/ s12885-017-3741-3. 
16. Ye L, Wu X, Wu T, et al. Meta-analysis of laparoscopic vs. open resection of gastric gastrointestinal stromal tumors. PLoS One. 2017;12(5):e0177193. doi:10.1371/journal.pone.0177193.

17. Kasetsermwiriya W, Nagai E, Nakata K, Nagayoshi Y, Shimizu S, Tanaka M. Laparoscopic surgery for gastric gastrointestinal stromal tumor is feasible irrespective of tumor size. J Laparoendosc Adv Surg Tech A. 2014;24(3):123-129. doi:10.1089/lap.2013.0433.

18. Lee JH, Kim Y, Choi JW, Kim YS. Correlation of imatinib resistance with the mutational status of KIT and PDGFRA genes in gastrointestinal stromal tumors: a meta-analysis. J Gastrointestin Liver Dis. 2013;22(4):413-418.

19. Adams HS, Bergstrom B, Haines B, Roberts N. Inflammatory fibroid polyp: an unusual cause of ileoileal intussusception. Case
Rep Surg. 2017;2017:6315934. doi:10.1155/2017/6315934.

20. Scherubl H, Faiss S, Knoefel WT, Wardelmann E. Management of early asymptomatic gastrointestinal stromal tumors of the stomach. World J Gastrointest Endosc. 2014;6(7):266-271. doi:10.4253/ wjge.v6.i7.266.

21. Rammohan A, Sathyanesan J, Rajendran K, et al. A gist of gastrointestinal stromal tumors: A review. World J Gastrointest Oncol. 2013;5(6):102-112. doi:10.4251/wjgo.v5.i6.102.

22. Huang JL, Zheng ZH, Wei HB, et al. Endoscopy-assisted laparoscopic resections for gastric gastrointestinal stromal tumors: a retrospective study. J Laparoendosc Adv Surg Tech A. 2017;27(2):110-114. doi:10.1089/lap.2016.0068. 